\title{
Too Legit to Rage Quit: Do Social Ties Impact Staying Power in eSports?
}

\author{
David M. Weber \\ Northern Arizona University \\ david.weber@nau.edu
}

\begin{abstract}
Sim racing, a sub-genre of eSports, is an online motorsports simulation where participants from around the world use specialized hardware to compete virtually in racing vehicles around a track. While most competitors complete the races they start, some opt to disconnect following a frustrating racing event. This is considered a "rage quit" in modern gamer slang. This research aims to identify the social factors associated with a rage quit through a binary logistic regression model populated with a unique dataset from iRacing, a major online sim racing platform, consisting of over 19,000 races over 4 racing seasons (12 months) in 2018, 300,000 individual race results, and 16,000 unique drivers. The findings suggest that social factors of past experience with competitors, racing with competitors in one's own region, and presence of other rage quitters all influence a driver's decision to rage quit.
\end{abstract}

\section{Introduction}

eSports have blossomed from humble beginnings as a niche hobby. Its earliest recorded event in 1972 featured Stanford University students competing in a game called Spacewar for a grand prize of a year subscription to Rolling Stone magazine. It is now an estimated \$1 billion industry in 2019 [1] where total prize pools reach $\$ 25.5$ million for the 2018 DOTA 2 International Competition (more than double the 2018 U.S. Open golf prize pool) [2]. Single eSports events like China's Battle of Balls Professional League have attracted 13,000 in-person viewers and 5 million online viewers [3]. Arlington, Texas is currently spending $\$ 10$ million of taxpayer funds to build a 100,000 square foot dedicated eSports arena [4]. The most popular Twitch stream, OverwatchLeague, has 1.5 million subscribers and can attract live online viewership exceeding $100,000^{1}$. While single-player

${ }^{1}$ twitchmetrics.net/c/137512364-overwatchleague gaming can be an isolating activity, eSports is inherently social, which involves a community of players and fans that interact both on and off the "field" of play [5, 6].

Many non-gaming activities are being gamified with the end goal of increased participation and engagement. At Northern Arizona University, undergraduate business students participate in "Pathways" events consisting of service work, guest speakers, and workshops. They must complete a certain number of these events to be admitted into the business program. The tool they use to track participation, Suitable ${ }^{3}$, offers students "achievements" for meeting milestones similar to what gamers experience on Xbox One, Playstation 4 , and Steam. There is even a constantly updating "leaderboard" for Pathways event completion.

Northern Arizona University wants its business students to attend these Pathways events (a requirement for enrollment in upper-division business courses) and to not give up or quit their progress, thus their adoption of the Suitable tool. Academics have published copious research on quitting jobs [7, 8], quitting relationships [9, 10], or quitting bad habits like smoking [11, 12], but research on quitting games is limited.

In contrast to staying power (one's "ability to maintain an activity or commitment despite fatigue or difficulty"4) rage quitting is a newer term in gamer vernacular (Google Trends analysis reveals the term began to rise sharply in web searches in $\left.2011^{5}\right)$. An official term definition is unavailable, but Urban Dictionary defines it as: "To stop playing a game out of an anger towards an event that transpired within the game"6. Edge [13] declares that a rage quit "occurs when a player becomes frustrated with the current game state and decides to intentionally abandon the game" and Przybylski et al. [14] define it as "the act of disconnecting gaming equipment, sometimes violently" resulting from

\footnotetext{
${ }^{2}$ nau.edu/franke/pathways-professional-leadership/

${ }^{3}$ suitable.co/universities/

${ }^{4}$ merriam-webster.com/dictionary/staying\%20power

5 trends.google.com/trends/explore?date=allq="rage $\% 20$ quit"

${ }^{6}$ urbandictionary.com/define.php?term=ragequit
} 
"sudden, high-intensity negative emotional experiences in response to feeling overwhelmed by competitors." It has a negative connotation and rage quitters are discussed with disdain in online forums and discussion boards. In Dota2, frequent rage quitters face consequences of being placed in a lower priority game queue [13]. Although the term is primarily used in a context of video gaming, the concept has a wider application including sports, board games, game shows, and other gamified activities.

Rage quitting negatively impacts other participants' experience, since especially in team-based competitions it leaves teammates short-handed. It also negatively impacts service providers, because rage quits stem from frustration and anger and those participants are unlikely to remain members of the service resulting in lost subscription or advertising revenue.

One goal we have for Dota 2 is to have as many people playing and enjoying the game as possible. To do so, we suspected we'd need to encourage behaviors that have positive effects on the game and community and discourage behaviors that have the opposite effect- like causing other players to play less or not at all [15]. - Dota 2 Team

Understanding who rage quits and why they rage quit has powerful ramifications for social network creators, gaming service administrators, and any other context in which tasks are gamified. If we can predict who will rage quit or what causes people to rage quit, then service providers can implement changes to retain more participants.

This research looks at a host of variables and their influence on a decision to rage quit, but emphasizes the impact of social factors. eSports are competitive by nature, just like in physical sports. Regardless if the sport is with a team (e.g. soccer, baseball) or an individual effort (e.g. singles tennis, boxing), the presence of, and relationships with, teammates and competitors play an important role in athletes' decisions while on the field of play. The arena of eSports provides a similar environment.

The research presented in this paper aims to answer the following questions: (1) What social factors impact rage quitting? and (2) What non-social factors impact rage quitting? It also sets a foundation for answering two future research questions: (3) How can social networks and game/gamified service providers reduce rage quitting? and (4) Does game-level (micro) quitting lead to service-level (macro) quitting?

The remainder of the paper is structured as follows: Section 2 describes our research context of sim racing and iRacing in particular. Section 3 details the theoretical background and justification for hypotheses. Section 4 describes the data and data collection process. Section 5 introduces the estimation model. Section 6 presents results of the analysis and discusses their meaning. Section 7 concludes with implications of these findings in gaming and other contexts.

\section{Research context}

eSports competition can be player vs. player (PvP), first person shooter (FPS), real-time strategy (RTS), or multiplayer online battle arena (MOBA $)^{7}$. Within the PvP type are sub-genres including fighting games, sports games, and racing games. Racing games are further classified as arcade racing marked by fantasy locations, power-ups, unnatural physics, and a lower learning curve and sim racing, which emphasizes realistic physics, cars, and track locations. A mix of the two is considered a sim-cade ${ }^{8}$. The following subsections introduce sim racing and specifically the iRacing platform to orient the reader in understanding the dataset and its variables.

\subsection{Sim racing}

Sim racing involves a user manipulating specialized hardware (steering wheels, pedals, shifters, and button boxes) to control a virtual car around a virtual track through simulator software running on a PC or gaming console. The driver sees the race track from the perspective of the vehicle's cockpit on monitors, screens, or through a virtual reality (VR) headset.

Advancements in hardware, processing power, telemetry, and scanning methods have diminished the gap between sim racing and real world racing. Motoring media publisher TopGear brought Greger Huttu, a sim racing world champion from Finland who does not possess a driver's license and had never driven a real car, to Road Atlanta to race a 260bhp Star Mazda open-wheeler race car and determine how well he could translate his sim racing experience to the real world. The coaches were impressed with his speed. "The telemetry confirms it. His braking points are spot on. He's firm and precise on the throttle. And in the fastest corner, he's entering at $100 \mathrm{mph}$ compared to an experienced driver's 110 - a sign of absolute confidence and natural feel for grip." [16]. Professional race car drivers including Dale Earnhardt, Jr., Kyle Larson, and Joey Logano use sim racing to train and learn new tracks ${ }^{9}$.

\footnotetext{
${ }^{7}$ discoveresports.com/what-are-the-game-types/

${ }^{8}$ n3rdabl3.com/2017/08/racing-sim-arcade-differences/

${ }^{9}$ iracing.com/testimonials/
} 


\section{2. iRacing}

iRacing (short for Internet Racing), is a subscription-based sim racing platform developed by iRacing.com Motorsport Simulations in Bedford, MA and made available to the public in 2008. One of its co-founders, John Henry, is also principal owner of the Boston Red Sox and Liverpool Football Club. iRacing aims to offer the most realistic and authentic racing experience to its members. They use LIDAR technology ${ }^{10}$ to laser scan real-world race tracks which are accurate to one millimeter. For cars, iRacing developers use telemetry data and "scan, weigh, and measure each part of the actual race cars and assemble them digitally, giving users a mathematically correct vehicle to drive on the mathematically correct racing surface" [17].

iRacing's platform is unique, because unlike other sim racing software (e.g. Assetto Corsa, Project Cars 2, Automobilista, rFactor 2), competition is online-only. There is no single-player mode outside of practice hotlapping and no AI cars to race against. All competition is against other members of the iRacing service, which has seen steady growth and now boasts over 50,000 members, 50 official series, 400 private leagues $^{11}$, and a 2019 annual prize pool of $\$ 300,000^{12}$.

\subsection{Pricing model}

iRacing's pricing model is subscription plus content. Its members, referred to as iRacers, subscribe by paying monthly or annual fees (ranging from $\$ 13$ per month to $\$ 199$ per two years, though discounts are frequently available) giving them access to iRacing's base content of 18 cars and 18 tracks. Additional cars $(50+)$ and tracks $(60+)$ are available to license at prices from $\$ 11.95$ to $\$ 14.95$ each with discounts offered for purchasing multiple pieces of content in one transaction or by having reached a threshold of content purchased. iRacing has licensing partnerships with numerous real-world racing organizations and race car manufacturers and series (e.g. NASCAR, Renault, Mazda, Porsche, Blancpain, and McLaren) which afford them the rights to model and sell vehicle licenses to iRacers.

\subsection{Scoring}

To promote safe, organized, and competitive races, iRacing ranks each iRacer with two independent ratings: (1) iRating and (2) safety rating. An iRacer could have a

\footnotetext{
${ }^{10}$ oceanservice.noaa.gov/facts/lidar.html

11 iracing.com/overview/

12 iracing.com/iracing-to-award-300000-in-2019/
}

very high safety rating with a low iRating or vice-versa. Races occur in 4 main categories: Road, oval, dirt road (also known as rallycross), and dirt oval. iRacers have separate scores for iRating and safety rating in each category, but most iRacers focus on one racing category.

2.4.1. iRating. iRating, based on the Elo system used to rank chess players [18], is a measure of an iRacer's ability to win races and finish near the front of the pack. Each race is a zero-sum game where iRacers take a share of iRating from all drivers who finished behind them and lose iRating to all drivers who finished ahead of them. A driver who beats another driver with an iRating higher than them will gain more iRating than beating a driver with a lower iRating. All iRacers start their career in each category at 1,350 iRating. Given the zero-sum game of iRating, that number also serves as the mean iRating. In 2018, the highest iRating of more than 10,000 was held by Ty Majeski, a 22-year-old from Wisconsin whose iRacing success earned him a position as a development driver for Roush Fenway Racing [19].

2.4.2. Safety rating. Safety rating is a measure of a driver's ability to keep within the bounds of the track, maintain control of the car, and avoid contact with other cars. Each violation is considered an incident with different types of violations resulting in differing incident points. For example, having more than $50 \%$ of one's car off the track surface results in a $1 \mathrm{x}$ incident while a hard collision with another vehicle results in a $4 \mathrm{x}$ incident. Incidents do not assign blame, so in the case of a reckless driver who T-bones another car in the braking zone, both iRacers would be assessed a 4x incident. Most races have an incident limit (for example, in most races lasting less than an hour, the incident limit is $17 \mathrm{x}$ ). Once an iRacer surpasses that limit, the driver is immediately disqualified.

\subsection{License levels}

iRacing uses the number of corners driven per incident received as the measure to determine a driver's safety rating. The iRacer sees their safety rating in terms of license classes. All iRacers begin in the rookie $(\mathrm{R})$ license class and can progress through safe driving to D, C, B, A, and Pro licenses. Each level requires a progressively higher degree of safe racing and affords the iRacer opportunities to race in more challenging series. Similarly, license levels can be lost through amassing high incidents per corner. Once an iRacer crosses the threshold of a license level or sublevel (either an increase or decrease), their safety 
rating also immediately increases/decreases by 0.4 to minimize bouncing between levels. License levels are identified by a license level and a sublicense level (from zero to 4.99).

\subsection{Violations and protests}

iRacing has a protest system to minimize abuse of the platform's no-fault incident system. After races, members can protest competitors for violation of the iRacing Sporting Code, a 37-page document that all members must agree to abide by when registering. Violations include intentional wrecking, retaliation, blocking (swerving on a straight to avoid being passed), and abusive behavior or language in voice or text chat during a session. iRacing staff review each protest claim and can serve warnings or consequences including feature restriction or suspension/loss of membership.

\section{7. iRacing series}

Within each of the four racing categories, iRacing schedules dozens of official 12-week series. Each series runs with a particular car (e.g. Formula Renault 2.0) or class of car (e.g. GT3) for the entire season, changing tracks weekly. Races run as frequently as hourly or as infrequently as weekend only, depending on the popularity of the series. All series have a minimum license class required to participate. Rookie series all use the base iRacing content included with subscriptions and include lower-powered cars at less-challenging tracks. The fastest cars and most challenging tracks are limited to series which require higher license levels $(\mathrm{C}$, B, or A) For example, iRacers who want to compete in the popular VRS GT3 Sprint series must first earn and maintain a $\mathrm{B}$ license.

\subsection{Race process}

Once an iRacer registers for a race, they are required to participate or else forfeit - the equivalent of having finished last in the race. iRacing divides up the registered drivers into splits based on (1) the number of cars accommodated on the track's starting grid and/or pit lane and (2) the drivers' iRatings. If 60 iRacers register for a race on a track that accommodates 20 cars, the 20 drivers with the highest iRatings will comprise the top split, the 20 drivers with the lowest iRatings will comprise the bottom split, and the 20 remaining drivers will comprise the middle split. A brief practice session ensues followed by the qualifying session where drivers have a set number of minutes and/or laps to set their single best lap time. The fastest qualifying time among the drivers in the split will start the race on pole position with each slower qualifying time on the grid behind that driver. Drivers who do not qualify start on the grid behind qualifiers, with their iRating determining their grid position. Races last a set number of minutes or laps, with penalties (black flags) automatically assessed throughout the race for false starts, cutting corners, speeding in the pit lane, etc. Such penalties would require a driver to enter the pit lane for a stop-and-go or stop-and-hold for a number of seconds. Drivers with damaged vehicles may enter the pit lane for repairs. If the vehicle is too damaged to drive to the pit lane, they can request a "tow" to their pit stall which incurs a time penalty before the repair ensues. After the race, iRacing adjusts each driver's iRating and safety rating according to their performance on the track and strength of field (average iRating of all iRacers in the split).

\section{Theory and hypotheses}

This section introduces the existing literature and theories (concentrated in social network, turnover, and organizational behavior theory) that justify three hypotheses for this study.

\subsection{Social network theory}

Social network theory encourages us to view participants as nodes with ties linking them with others [20, 21]. Two individuals that share similar characteristics or with a history of interactions would form stronger ties. These ties are more important than individual agency, an individual's ability to influence her/his own success. Figure 1 depicts a social network where participant " $C$ " is in isolation, the strongest link exists between participants "A" and "B", and a weak link exists between participants "A" and "D".

Bridging social network theory with turnover theory, Feeley and Barnett [22] posited that the more communication employees have with employees that quit are also more likely to leave their job and employees on the "periphery" (with few social ties) are at a greater risk of turnover. In Figure 1, participant "C" followed by participant "D" are most likely to quit and participant "A" is least likely to quit. Organizational psychologists refer to this as kinship responsibility [23, 24, 25].

\subsection{Turnover and organizational behavior theory}

The decades-old body of scientific literature on turnover seeks to determine how and why employees quit jobs. Although quitting a job (considered macro quit) differs from rage-quitting a competition/game (a micro quit), these theories justify the hypotheses and this 


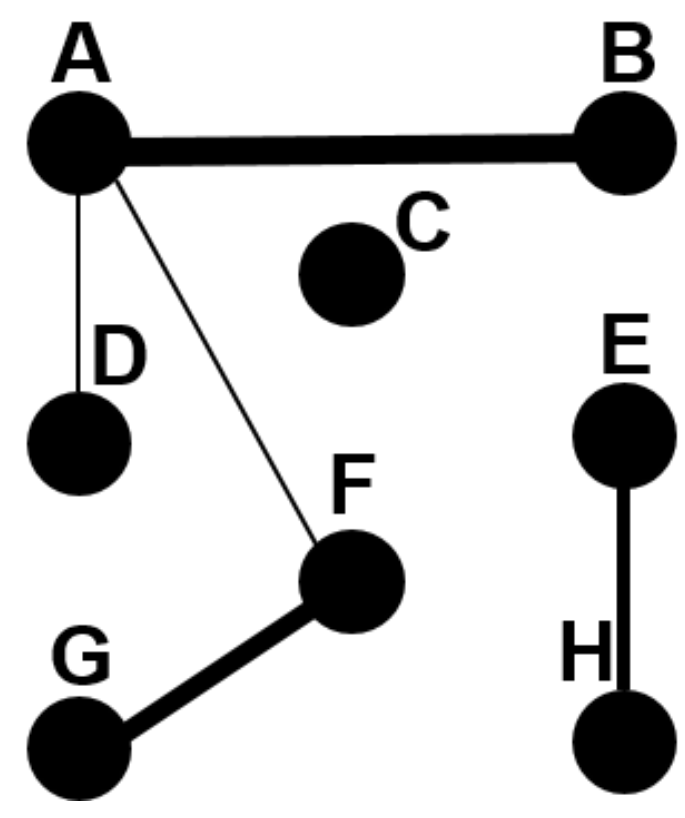

Figure 1. Social network nodes and links

research will explore if the factors of a macro quit still apply in the context of a micro quit. Using Facebook as an example in another context, a micro quit would be a user ending their current session by closing their browser, navigating to another web site, or closing the app. A macro quit would be a user deleting their account.

Anger and frustration also lead to employee turnover $[26,27,28]$ and job performance influences quitting [29, 30]. Porter et al. [31, 32] determined that organizational commitment influences turnover. Quitting occurs in clusters, referred to as a "snowball effect" [33]. In this regard, employees act in alignment with contagion theory, or that opinions, ideas, and actions spread through a network similar to a communicable disease $[34,35]$.

\subsection{Hypotheses}

Assuming that frustrating gaming experiences lead to rage quits similar to how frustration and anger lead to employee turnover, organizational behavior theories justify three hypotheses for this study. iRacing is a paid service and commitment to this service can be proxied by tenure of one's membership similar to how commitment to a job can be measured by length of employment. In the same way that employees are motivated to stay in their jobs to not let down their family and friends, eSports competitors are motivated to stay when surrounded by competitors with whom they have social ties, justifying hypothesis 1: Drivers with fewer competitors in his/her region are more likely to rage quit and hypothesis 2: The less prior race experience a driver has with his/her competitors, the more likely they are to rage quit. Contagion theory justifies hypothesis 3: If a driver rage quits, other drivers in the race are more likely to rage quit.

\section{Data and variables}

This section describes the data collection process, why this particular set of data is appropriate to test the hypotheses, how calculated variables were determined, defines the variables, and presents summary statistics.

\subsection{Data collection process}

A benefit to drivers on iRacing's service is the quantity of metrics they provide; from macro-level trends to the incidents and times that make up an individual lap in a race. The data from iRacing is ideal for investigating rage quitting given the quantity of variables available and the quantity of races that take place.

iRacing's data is available to users via active web pages, but would be too time and labor intensive to collect manually. An iRacer from Tasmania developed a Python library ${ }^{13}$ that retrieves data from iRacing on members, cars, tracks, series, race results, incidents, and lap results. I used these libraries to scrape data from iRacing and transform it into a format that populated rows in several CSV files.

Microsoft Excel and Python were used to add several "calculated" variables (e.g. cusp of promotion/demotion, rage quit, performance in previous race, number of other drivers in same race from the same region, number of previous races with competitors, etc.). The final data set is completely unique and no academic paper revealed in searches at the time of this writing uses data from iRacing.

\subsection{Data subset rationale}

All data come from the four 12-week series in 2018 comprising the entire calendar year. In 2018, hundreds of thousands of races occurred in all four disciplines across all series in iRacing. Each series differs with respect to license requirements, skill level, incident limits, duration of races, and frequency of races. Data in this analysis are limited to a single race series, the Skip Barber Race Series. All races involve a single vehicle, the Skip Barber Formula $2000^{14}$, a 150-horsepower

\footnotetext{
${ }^{13}$ github.com/jeysonmc/ir_webstats

${ }^{14}$ iracing.com/cars/skip-barber-formula-2000/
} 
4-cylinder open-wheeled race car capable of top speeds reaching $135 \mathrm{mph}$. This particular series was chosen for a number of reasons.

(1) The series uses a mix of free tracks and paid tracks. (2) The car is not included in iRacing's free content and must be purchased for $\$ 11.95$, representing a financial commitment of the drivers that race in this series. (3) The series requires a D-level or better license, but is popular among all driver levels. In D-level races, drivers may "fast repair" their car one time in a race simply by stopping in their designated pit stall and receive an instantaneous repair. Subsequent repairs can take several minutes to repair in the pit stall depending on the severity of the damage. This fast repair feature does not exist in $\mathrm{C}$ and higher level race series. (4) Races are consistent in duration - around 25 minutes per race. (5) $99.44 \%$ of races "went official," meaning it had a minimum of 6 drivers and race results impacted drivers' iRatings and safety ratings. (6) Races occur hourly. Many other series are less popular and are scheduled every other hour or only on weekends.

\subsection{Determination of rage quit}

Rage quit is not a variable provided by iRacing and must be determined with the data available. I construct a dummy variable where 0 is not a rage quit and 1 is a rage quit. Since a rage quit is a frustrating event that leads to dropping out of the competition, I set the value of our dummy variable to 1 if both of the following are true: (1) the user accumulated a minimum of $2 x$ incident points and (2) quit the race within the first 5 laps. Incident points are tied to the safety rating of an iRacer and accrue throughout the laps of a race. An ideal data set would include Likert-scale variables on the emotions and feelings of each participant during or after the race, or a self-declared reason for why they quit.

This variable is our best proxy for a rage quit. I acknowledge this determination could assign false positives to a racer who amassed $2 \mathrm{x}$ incident points, but disconnected because their internet connection failed or they had to attend to a crying baby or barking dog. False negatives are also a possibility, since a driver could possibly rage quit with simply a $1 \mathrm{x}$ incident (just one off-track, which is highly unlikely) or after 5 completed laps (more likely, but some drivers quit early from a race because a repair would take more time than remaining in the race). While not perfect, the signs and significance of parameter estimates remained unchanged when varying the rage quit factors, giving us confidence that this dummy variable is adequately measuring rage quitting.

\subsection{Determination of gender}

Driver data is largely related to their race history and performance, which are employed as variables in our analysis. Demographic data is limited. Drivers can post their photos and complete unstructured text fields listing their hobbies, favorite cars, and favorite films among others, but these fields are unstructured and frequently written in the native language of the iRacer. The driver's tenure on the service and geographic region are both captured. Gender is not explicitly available, but I employed a technique using the Social Security Administration's 500 most popular boys and girls birth names from 1980 to make a determination of gender from the iRacer's listed first name [36, 37, 38]. In a separate analysis that includes gender as a covariate, I limited the data to the USA, Canada, New Zealand, Australia, the United Kingdom, and Ireland, which are Anglophone countries where names would be similar to those listed in the Social Security Administration list. This analysis is separated due to the decreased observations. This research assumes a binary gender determination.

\subsection{Variable definition}

Table 1 lists variable identifiers in the model along with their descriptions. The variables in the analysis are a subset of the data available and collected through the scraping process described earlier and chosen to test the hypotheses and provide controls to the model. The variables of interest (the social factors) begin with the prefix $S O C$. Five variables with the subscript $(n-1)$ represent attributes from the iRacer's previous race.

\subsection{Summary statistics}

After dropping unofficial races $(0.56 \%$ of the race results), the final data set comprises 16,622 unique drivers competing in 19,105 races with 306,801 race results. All records were complete with no missing data. Each race had on average 16 iRacers. Drivers averaged a participation of 18 Skip Barber races in 2018. The minimum was shared by 2,952 drivers participating in only one race and the maximum participation for a single driver was 1,373 races. $7.97 \%$ of the race results were coded as a rage quit given the determination described earlier in section 4.3.

\section{Estimation model}

With the data collected and variables declared, I test the hypotheses through an empirical estimation model. This section defines the model, fits data to the model, 
Table 1. Variable definitions

\begin{tabular}{|c|c|}
\hline Variable & Definition \\
\hline ragequit & $\begin{array}{l}0: \text { driver did not rage quit, } 1: \text { driver } \\
\text { rage quit }\end{array}$ \\
\hline socrq & \# of other drivers that rage quit \\
\hline sochistory & \# previous races with opponents \\
\hline socregion & $\begin{array}{l}\text { \# drivers in the same race split from } \\
\text { the same region as the driver }\end{array}$ \\
\hline splitof & \# splits at a given race start time \\
\hline startpos & $\begin{array}{l}\text { Driver's position on the starting } \\
\text { grid, based on qualifying time }\end{array}$ \\
\hline carnum & iRating ranking within the split \\
\hline region & A series of 36 regional dummies \\
\hline irating & iRating entering the race \\
\hline license & License level entering the race \\
\hline tenure & Years on iRacing service \\
\hline prevstarts & $\begin{array}{l}\text { \# previous road race starts the driver } \\
\text { has on iRacing entering the race }\end{array}$ \\
\hline incidentavg & $\begin{array}{l}\text { Average incidents that the driver } \\
\text { has in all previous races entering the } \\
\text { race }\end{array}$ \\
\hline fieldsize & \# drivers in the split \\
\hline split & Split number (1 = top split) \\
\hline fieldstrength & Average iRating of drivers in split \\
\hline paidtrack & $\begin{array}{l}0: \text { track is free content within } \\
\text { iRacing, 1: Track must be } \\
\text { purchased by driver to compete }\end{array}$ \\
\hline cusppromotion & $\begin{array}{l}\text { 1: Driver enters race within } 0.15 \text { of } \\
\text { earning a license promotion }\end{array}$ \\
\hline cuspdemotion & $\begin{array}{l}\text { 1: Driver enters race within } 0.15 \text { of } \\
\text { a license demotion }\end{array}$ \\
\hline $\operatorname{finpos}_{(n-1)}$ & Finishing position in the prior race \\
\hline $\begin{array}{l}\text { irating } \\
\text { change }_{(n-1)}\end{array}$ & $\begin{array}{l}+/- \text { change in iRating from their } \\
\text { previous race }\end{array}$ \\
\hline $\begin{array}{l}\text { license } \\
\text { change }_{(n-1)}\end{array}$ & $\begin{array}{l}+/- \text { change in license rating from } \\
\text { their previous race }\end{array}$ \\
\hline incidents $_{(n-1)}$ & $\begin{array}{l}\text { \# incidents amassed by the driver in } \\
\text { their previous race }(0 \text { : incident-free } \\
\text { clean race) }\end{array}$ \\
\hline ragequit $_{(n-1)}$ & $\begin{array}{l}0: \text { driver did not rage quit previous } \\
\text { race, } 1 \text { : driver rage quit prev. race }\end{array}$ \\
\hline
\end{tabular}

analyzes tests of fit, and presents parameter estimates.

\subsection{Logistic regression}

Logistic regression is an appropriate model for this study, since it models the probability of a binary outcome - whether or not the participant in a race rage quit. One advantage of using this method is that the model is not affected by obtaining data retrospectively, as in the case of this study. The outcome variable in this model below is the probability that the driver rage quit.

$$
\log \left(\frac{p_{\text {ragequit }=1}}{p_{\text {ragequit }=0}}\right)=\beta_{0}+\beta_{1} \text { socr } q+\beta_{2} \text { sochistory }+
$$$$
\beta_{3} \text { socregion }+\beta_{4 \ldots N} \text { controls }
$$

In the abbreviated depiction of the estimation model above, the variables of interest are socrq, sochistory, and socregion. controls represent the 55 other (19 control variables and 36 regional dummies) independent variables in the model. The parameter estimates of $\beta_{1}$ through $\beta_{N}$ represent the relative change in the probability of a rage quit for a unit change in an explanatory variable. $\beta_{0}$ is an intercept and the model includes no error term; since it does not model the race result, but a probability.

\subsection{Data fit to model}

SPSS imported the final data set in a single flat table, built the estimation model, calculated parameter estimates, and ran goodness of fit tests. Logistic regression models do not produce a true R-squared value. The Nagelkerke [39] pseudo R-squared value is 0.097 , suggesting that the variables in the model explain $9.7 \%$ of the variance in the rage quit outcome. An analysis of the correlation matrix revealed that independent variables are indeed measuring unique characteristics of the race results with the only pairwise correlation above 0.7: fieldstrength and irating have a pairwise correlation of 0.74 .

\subsection{Parameter estimates}

Table 2 lists the parameter estimates along with their significance and standard errors (region consists of 36 dummy variables thus its exclusion from the table). Positive and significant coefficients represent variables that, in the model, will increase the probability of a rage quit the larger the value. For example, I interpret the parameter estimate for splitof to mean that the more splits for a particular race, the odds of a driver rage quitting are higher. Likewise, negative and significant coefficients represent variables that will decrease the probability of a rage quit the larger the value. For example, I interpret the parameter estimate for sochistory to mean that the more race history that a driver has with his or her competitors, the less likely that driver is to rage quit.

\section{Results and discussion}

The more competition within one's home region, the stronger the staying power for that driver. 
Table 2. Estimation results for regression model

\begin{tabular}{|c|c|c|}
\hline Variable & Coeff. & Std. Err. \\
\hline socrq & $.240^{* * * *}$ & .005 \\
\hline sochistory & $-.005^{* * *}$ & .000 \\
\hline socregion & $-.009^{*}$ & .005 \\
\hline splitof & $.077^{* * * *}$ & .009 \\
\hline startpos & $.020^{* * * *}$ & .002 \\
\hline carnum & $-.026^{* * * *}$ & .002 \\
\hline irating & $.000^{* * *}$ & .000 \\
\hline license & $-.066^{* * *}$ & .003 \\
\hline tenure & $.014^{* * * *}$ & .003 \\
\hline prevstarts & $.000^{*}$ & .000 \\
\hline incidentavg & $.023^{* * *}$ & .006 \\
\hline fieldsize & $.009^{* *}$ & .004 \\
\hline split & -.014 & .011 \\
\hline fieldstrength & $.000^{* * * *}$ & .000 \\
\hline paidtrack & $.518^{* * * *}$ & .023 \\
\hline cusppromotion & $-1.309^{* * * * *}$ & .414 \\
\hline cuspdemotion & $.348^{* * * *}$ & .117 \\
\hline $\operatorname{finpos}_{(n-1)}$ & $.023^{* * * *}$ & .004 \\
\hline iratingchange $_{(n-1)}$ & $.003^{* * * *}$ & .000 \\
\hline licensechange $_{(n-1)}$ & $-.151^{* * *}$ & .064 \\
\hline incidents $_{(n-1)}$ & .001 & .003 \\
\hline ragequit $_{(n-1)}$ & $.991^{* * * *}$ & .028 \\
\hline \multicolumn{3}{|c|}{$*=\mathrm{p}<.1, * *=\mathrm{p}<.05, * * *=\mathrm{p}<.01$} \\
\hline
\end{tabular}

Both voice and text chatting occurs between drivers before, during, and after a race. In, say, races with many Italians, the Italians will dominate the radio with their banter. As expected, the more racers from a driver's region, the less likely the driver is to rage quit, supporting hypothesis 1.

As expected, the more race history that a driver has with his or her competitors, the less likely they are to rage quit, supporting hypothesis 2 . This could be due to a greater race enjoyment being surrounded by familiar names making it easier to endure frustrating race events. Or the motivation could come from wanting to avoid the embarrassment and shame of an early quit when surrounded by more familiar peers.

Competitors' rage quitting impact rage quitting, suggesting that rage quitting occurs in clusters, supporting hypothesis 3. An further explanation for this could be a catastrophic crash in the first corner involving many vehicles, leading to many drivers rage quitting together.

Other non-social control variables in the model offer some interesting findings as well. Drivers that start the race further in the back of the starting grid are more likely to rage quit. This can be attributed to mistakes made in qualifying that lost them time, putting the driver into a frustrated mood entering the race. Also, the further back on the starting grid, the less skilled drivers surround the driver, resulting in more crashes. Similarly, the higher a driver's relative rating to the other racers (the car number), the more likely to rage quit. The more incidents a driver has on average in their iRacing history, the more likely he/she is to rage quit a race.

Rage quits occur more regularly in races with more splits. In these races drivers race against more similarly skilled opponents (e.g. a race with an iRating range of 1,400 to 1,600). An explanation for this is that drivers with similar skill are more likely to have lap times close to their opponents, resulting in closer racing and greater opportunities for frustrating incidents leading to rage quits.

As expected, the higher license level entering a race, the less likely a driver is to rage quit. Since license levels are based on corners per incident, accruing several incidents in few corners and then quitting is a poor strategy to advancing in the license classes.

Elements of previous race performance significantly impacts rage quitting. A worse race finishing position, loss in iRating, presence of indents, or rage quitting in the previous race all increase the probability of a rage quit. Change in license level from the previous race is insignificant in the model. The expectancy theory of motivation [40] posits that people are motivated by how they expect to perform and their previous race is the most recent outcome.

I expected that paid tracks would reduce the likelihood of rage quitting since participants have a financial investment in the track, but the data support the opposite. It's the free tracks that have less rage quitting. An explanation for this paradox is that since all drivers have access to free tracks, they likely have more experience on them and can drive more mistake-free than on the paid tracks.

I ran a separate model including gender as a covariate, because the method for determining gender cut the data set by two-thirds. The expectation was that females would be more likely to rage quit than their male counterparts, because females are a significant minority in sim racing ( $0.9 \%$ of the sample data set) and organizational behavior research finds that females are more likely to quit if the sex makeup of an organization is predominantly male [8]. The data support the converse even though females have a higher incident average per race than males, suggesting women possess more control over frustration- and anger-inducing race events.

iRacing's license system avoids frequent jumping between license levels by increasing/decreasing a driver's license level by 0.4 every time they cross a 
major license level threshold. A driver on the "cusp" of a promotion or demotion is aware of this entering a race. The results were interesting in that being on the cusp of a promotion makes a driver less likely to rage quit, but being on the cusp of a demotion makes a driver more likely to rage quit. Gray's biophysiological theory of personality [41] explains this outcome since the risks of punitive actions is not as strong of a motivator as the proposition of reward for good performance.

The model suggests the region of drivers influences rage quit decisions. Regions with drivers that are more likely to rage quit include America, Latin America, and Italy. Some of the regions with drivers that are less likely to rage quit include Iberia and France. Further exploration on the cultural characteristics of these and other regions could provide interesting insights.

\section{Conclusion}

This paper contributes an important finding to the information systems, gaming, and human behavior disciplines: Social ties do indeed bolster staying power in eSports. Within iRacing, drivers that share the grid with members of their own region or drivers they have raced against in the past are less likely to rage quit. Also, rage quitting has a social contagion "snowball" effect. This section lists some limitations of this study, suggests applicability to other domains, and shares implications for theory and practice.

\subsection{Limitations}

As mentioned in section 4.3, false-positives and false-negatives are both possible with the determination of rage quit used in this study. Sim racing as a hobby requires a serious investment in hardware and software and therefore comprises a different demographic than, say gamers playing Fortnite (a popular free-to-play) with a much lower hardware investment (a game console or even a smartphone). This study explores rage quitting in only one context. The results of testing hypothesis 4 will certainly differ in most other eSports contexts. In sim racing, similarly skilled drivers in the same race can result in closer racing and thus more contact. In a FIFA soccer eSports tournament, the converse may be true where similarly skilled opponents results in less frustration. The $(n-1)$ race performance variables only considered the single prior race, but could be extended to factor a greater history. This dataset does not observe communication data (text and voice chat), which was found to be a key determinant of premature quitting in Dota 2 [15].

\subsection{External validity, practical/theoretical implications, and future research}

To retain a large and satisfied user base, game service providers can implement practical changes, including: (1) place competitors from the same region or with shared race history in the same split, (2) encourage partitipants with a poor result in their prior competition with strategy tips to avoid frustrating situations in the future, and (3) offer more competitions with free/included content. Consider with an advanced model, rage quit predictions being made in real-time and providing players at their most frustrating moments with, say, a loot box to give an extra boost of encouragement.

Testing these claims in other contexts is a logical next step, although one would expect findings to be similar given the theoretical foundations that form the foundations of the hypotheses. If these phenomena can also be observed in, say, a social network like Facebook with over 1 billion accounts, motivation is strong to consider how to create an environment that enhances social ties to lengthen sessions and maximize advertising revenue. A next theoretical step would be to further explore the relationship between a micro quit and a macro quit. Does a pattern of frustrating micro rage-quit events lead to a macro quit decision? With that knowledge, social network providers could predict and prevent some users from completely abandoning their services. It is my hope that I and my fellow information systems researchers freely explore these questions to advance our understanding of these phenomena.

\section{References}

[1] H. Russ, "Global esports revenues to top $\$ 1$ billion in 2019: report." reuters.com/article/usvideogames-outlook-idUSKCN1Q11XY，2019. Last accessed: May 24, 2019.

[2] C. Ingraham, "The massive popularity of esports, in charts." washingtonpost.com/business/2018/ 08/27/massive-popularity-esports-charts/, 2018. Last accessed: May 24, 2019.

[3] S. Chan, "Mobile esports ascends in Asia." venturebeat.com/2018/02/08/newzoo-mobile-esportsascends-in-asia/, 2018. Last accessed: June 6, 2019.

[4] A. Albright, "Cowboys. Rangers. Fortnite? A texas city bets on esports stadium." bloomberg.com/news/articles/2018-08-31/cowboysrangers-fortnite-texas-city-bets-on-esports-stadium, 2018. Last accessed: May 24, 2019.

[5] Y. Seo and S. U. Jung, "Beyond solitary play in computer games: The social practices of esports," Journal of Consumer Culture, vol. 16, no. 3, pp. 635-655, 2016.

[6] G. Freeman and D. Y. Wohn, "Social support in esports," in Proceedings of the Annual Symposium on Computer-Human Interaction, pp. 435-447, 2017. 
[7] P. W. Hom, J. D. Shaw, T. W. Lee, and J. P. Hausknecht, "One hundred years of employee turnover theory and research," Journal of Applied Psychology, pp. 530-545, 2017.

[8] A. L. Rubenstein, M. B. Eberly, T. Lee, and T. R. Mitchell, "Looking beyond the trees: A meta-analysis and integration of voluntary turnover research," Academy of Management Proceedings, vol. 2015, no. 1, pp. 23-65, 2015.

[9] J. M. Gottman, What Predicts Divorce?: The Relationship Between Marital Processes and Marital Outcomes. New York, NY: Psychology Press, 2014.

[10] P. R. Amato, "Research on divorce: Continuing trends and new developments," Journal of Marriage and Family, vol. 72, no. 3, pp. 650-666, 2010.

[11] G. C. Kabat and E. L. Wynder, "Determinants of quitting smoking," American Journal of Public Health, vol. 77, no. 10, pp. 1301-1305, 1987.

[12] S. Cohen and E. Lichtenstein, "Perceived stress, quitting smoking, and smoking relapse," Health Psychology, vol. 39 , no. 4 , p. 466, 1990.

[13] R. Edge, "Tr 13-024: Predicting player churn in multiplayer games using goal-weighted empowerment,' pp. 1-8, 2013 .

[14] A. K. Przybylski, C. S. Rigby, E. L. Deci, and R. M. Ryan, "Competence-impeding electronic games and players aggressive feelings, thoughts, and behaviors," Journal of Personality and Social Psychology, vol. 106, no. 3, pp. 441-499, 2014.

[15] "Communication reports." http://blog.dota2.com/ 2013/05/communication-reports/, 2013. Last accessed: June 6, 2019.

[16] D. Read, "Geek, rebooted." topgear.com/car-news/ gaming/geek-rebooted/, 2013. Last accessed: May 24, 2019.

[17] J. Brown, "iRacing.com racing simulator: The answer to all your racing prayers and your budget." caranddriver.com/features/iracingcomracing-simulator/, 2008. Last accessed: May 24, 2019.

[18] R. Coulom, "Computing elo ratings of move patterns in the game of go," Icga Journal, vol. 30, no. 4 , pp. 198-208, 2007.

[19] A. Lawrence, "How iRacing is democratizing motorsports," The Atlantic, 2018.

[20] M. S. Granovetter, "The strength of weak ties," American Journal of Sociology, vol. 78, no. 6, pp. 347-367, 1977.

[21] L. C. Freeman, D. Roeder, and R. R. Mulholland, "Centrality in social networks: Ii. experimental results," Social Networks, vol. 2, no. 2, pp. 119-141, 1979.

[22] T. H. Feeley and G. A. Barnett, "Predicting employee turnover from communication networks," Human Communication Research, vol. 23, no. 3, pp. 370-387, 1996.

[23] J. L. Price and C. W. Mueller, "A causal model of turnover for nurses," Academy of Management Journal, vol. 24, no. 3, pp. 543-565, 1981

[24] P. W. Hom and Z. Xiao, "Embedding social networks: How guanxi ties reinforce chinese employees retention," Organizational Behavior and Human Decision Processes, vol. 116, no. 2, pp. 188-202, 2011.
[25] K. W. Mossholder, R. P. Settoon, and S. C. Henagan, "A relational perspective on turnover: Examining structural, attitudinal, and behavioral predictors," Academy of Management Journal, vol. 48, no. 4, pp. 607-618, 2005.

[26] J. Weitz and R. C. Nuckols, "Job satisfaction and job survival," Journal of Applied Psychology, vol. 39, no. 4, pp. 294-300, 1955.

[27] A. H. Brayfield and W. H. Crockett, "Employee attitudes and employee performance," Psychological Bulletin, vol. 52, no. 5, pp. 396-424, 1955

[28] C. L. Hulin, "Effects of changes in job-satisfaction levels on employee turnover," Journal of Applied Psychology, vol. 52, no. 2, pp. 122-126, 1968.

[29] R. M. Steers and R. T. Mowday, "Employee turnover and postdecision accommodation processes," Research in Organizational Behavior, vol. 3, pp. 235-282, 1981.

[30] E. F. Jackofsky, "Turnover and job performance: An integrated process model," The Academy of Management Review, vol. 9, no. 1, pp. 74-83, 1984.

[31] L. W. Porter, W. J. Crampon, and F. J. Smith, "Organizational commitment and managerial turnover: A longitudinal study," Organizational Behavior Human Performance, vol. 15, no. 1, pp. 87-98, 1976.

[32] L. W. Porter, R. M. Steers, R. T. Mowday, and P. Boulian, "Organizational, work, and personal factors in employee turnover and absenteeism," Psychological Bulletin, vol. 80, no. 2, pp. 151-176, 1974.

[33] D. Krackhardt and L. W. Porter, "The snowball effect: Turnover embedded in communication networks," Journal of Applied Psychology, vol. 71, no. 1, pp. 50-55, 1986.

[34] N. A. Christakis and J. H. Fowler, "Social contagion theory: examining dynamic social networks and human behavior," Statistics in Medicine, vol. 32, no. 4, pp. 556-577, 2013.

[35] S. Aral and D. Walker, "Creating social contagion through viral product design: A randomized trial of peer influence in networks," Management Science, vol. 57, no. 9, pp. 1623-1639, 2011.

[36] J. D. West, J. Jacquet, M. M. King, S. J. Correll, and C. T. Bergstrom, "The role of gender in scholarly authorship," PloS One, vol. 8, no. 7, p. e66212, 2013.

[37] F. J. Riggins and D. M. Weber, "Information asymmetries and identification bias in p2p social microlending," Information Technology for Development, vol. 23, no. 1, pp. 107-126, 2017.

[38] W. Liu and D. Ruths, "Whats in a name? using first names as features for gender inference in twitter," in 2013 AAAI Spring Symposium Series, pp. 10-16, 2013.

[39] S. Menard, Applied Logistic Regression Analysis. Thousand Oaks, CA: Sage, 2002

[40] R. H. Rasch and H. L. Tosi, "Factors affecting software developers' performance: an integrated approach," $M I S$ Quarterly, vol. 16, no. 3, pp. 395-413, 1992.

[41] J. A. Gray, "The psychophysiological basis of introversion-extraversion," Behaviour Research and Therapy, vol. 8, no. 3, pp. 249-266, 1970. 